\title{
Buffering growth variations against water deficits through timely carbon usage
}

\section{Florent Pantin ${ }^{1+}$, Anne-Laure Fanciullino ${ }^{1,2,3}$, Catherine Massonnet ${ }^{1+}$, Myriam Dauzat ${ }^{1}$, Thierry Simonneau ${ }^{1}$ and Bertrand Muller ${ }^{1}{ }^{*}$}

\author{
1 UMR 759, Laboratoire d'Ecophysiologie des Plantes sous Stress Environnementaux, Institut de Biologie Intégrative des Plantes, Institut National de la \\ Recherche Agronomique, Montpellier, France \\ 2 UR 1103, Génétique et Ecophysiologie de la Qualité des Agrumes, Institut National de la Recherche Agronomique, San Giuliano, France \\ ${ }^{3}$ UR 1115, Plantes et Systèmes de Culture Horticoles, Institut National de la Recherche Agronomique, Avignon, France
}

\section{Edited by:}

Nate McDowell, Los Alamos National Laboratory, USA

\section{Reviewed by:}

Eryuan Liang, Institute of Tibetan

Plateau Research, Chinese Academy of Sciences, China

Ivika Ostonen, University of Tartu,

Estonia

\section{${ }^{*}$ Correspondence:}

Bertrand Muller, UMR 759

Laboratoire d'Ecophysiologie des

Plantes sous Stress

Environnementaux, Institut de

Biologie Intégrative des Plantes,

Institut National de la Recherche

Agronomique, Place Viala, 34060

Montpellier, France

e-mail: bertrand.muller@supagro. inra.fr

\section{${ }^{\dagger}$ Present address:}

Florent Pantin, Cell and

Developmental Biology, John Innes

Centre, Norwich, UK; Catherine

Massonnet, UMR 1137 INRA,

Université de Lorraine, Champenoux,

France.
Water stresses reduce plant growth but there is no consensus on whether carbon metabolism has any role in this reduction. Sugar starvation resulting from stomatal closure is often proposed as a cause of growth impairment under long-term or severe water deficits. However, growth decreases faster than photosynthesis in response to drought, leading to increased carbohydrate stores under short-term or moderate water deficits. Here, we addressed the question of the role of carbon availability on growth under moderate water deficits using two different systems. Firstly, we monitored the day/night pattern of leaf growth in Arabidopsis plants. We show that a moderate soil water deficit promotes leaf growth at night in mutants severely disrupted in their nighttime carbohydrate availability. This suggests that soil water deficit promotes carbon satiation. Secondly, we monitored the sub-hourly growth variations of clementine fruits in response to daily, natural fluctuations in air water deficit, and at contrasting source-sink balances obtained by defoliation. We show that high carbohydrate levels prevent excessive, hydraulic shrinkage of the fruit during days with high evaporative demand, most probably through osmotic adjustment. Together, our results contribute to the view that growing organs under moderate soil or air water deficit are not carbon starved, but use soluble carbohydrate in excess to partly release a hydromechanical limitation of growth.

\section{Keywords: leaf growth, fruit growth, water deficit, carbon starvation, carbon satiation, starch metabolism, VPD}

\section{INTRODUCTION}

Water stress critically impairs plant growth and affects primary productivity worldwide (Boyer, 1982; Zhao and Running, 2010). Understanding the mechanisms by which growth decreases under water stress is a long-standing matter of debate (Hsiao, 1973; Tardieu et al., 2011). Growth can be both defined as an irreversible increase in volume - expansive growth - and an accumulation of biomass into new structures - structural growth (reviewed in Pantin etal., 2012). During expansive growth, turgor pressure exceeds the resistance offered by the cell walls, leading to an enlargement of the walls and a net influx of water into the growing cells (Lockhart, 1965; Cosgrove, 1993). Structural growth is tightly dependent upon carbon supply to growing tissues, which are sites of intensive respiration (Bidel et al., 2000) and biosynthesis of carbon compounds essential for cell growth, such as cellulose, hemi-cellulose, or proteins (Smith and Stitt, 2007; Gibon et al., 2009). Under water stress, both water relations and carbon balance are impaired, because plants close their stomata to limit transpirational water loss, which also limits the carbon entry required for photosynthesis. Accordingly, plant growth under water stress could be reduced either because its water relations are unsuitable for growth - hydromechanical limitation - or because its carbon balance is low - metabolic limitation.

It has been often proposed that growth under water stress was modulated by hydromechanical constraints. Under water scarcity, water flux to growing cells is reduced because water potential gradients are disrupted (Tang and Boyer, 2002). Aquaporin closure by drought signals may also worsen the delivery of water to the growing tissues (Parent et al., 2009; Shatil-Cohen et al., 2011; Pantin et al., 2013). This leads to a drop in turgor pressure, that plants may counteract through osmotic adjustment, which partly relies on recruiting carbon solutes in the vacuole. Finally, water deficits tend to stiffen the cell walls (Fan et al., 2006; Zhang et al., 2011), making turgor pressure less efficient in driving growth. Thus, the hydromechanical limitation of growth by water deficits arises from an imbalance between the force required to enlarge the cell walls and the turgor pressure, which can be modulated by the mobilization of organic solutes.

The growth rate of sink organs is also tightly coordinated with carbon availability and this holds for roots (Freixes et al., 
2002; Yazdanbakhsh and Fisahn, 2010; Willaume and Pagès, 2011; Yazdanbakhsh et al., 2011), fruits (Génard et al., 1998; Lescourret et al., 1998; Léchaudel et al., 2005; Andriotis et al., 2012), flowers (Smith and Stitt, 2007; Dosio et al., 2011), or young leaves (Muller et al., 2001; Pantin et al., 2011). Moreover, under moderate water deficits, carbohydrate concentrations increase in growing tissues due to an uncoupling between growth rate and photosynthesis, the former being more sensitive than the latter (Muller et al., 2011). These differences of sensitivities have been reported for a long time (Boyer, 1970), and observed in a variety of species (Sadras and Milroy, 1996), including trees (Bogeat-Triboulot et al., 2007). They may at least partly originate from the strong resilience of the metabolic component of photosynthesis to water deficit (Kaiser, 1987; Flexas et al., 2004), while expansive growth is probably the most sensitive process to water stress (Hsiao, 1973). As a result, the correlations between growth rate and carbohydrate concentrations disappear under moderate water deficits (Muller et al., 2011).

These observations hold for moderate water deficits. Contrastingly, under long-term or severe water deficit, photosynthesis can be so severely reduced that plants may enter into carbon starvation, therefore provoking a metabolic limitation of growth or even plant death (McDowell, 2011; Quirk et al., 2013; Sevanto et al., 2013). Carbon starvation could be particularly critical for isohydric species which prevent excessive drop of their leaf water potential by an early closure of their stomata (McDowell et al., 2008).

Increases in carbohydrate concentration following moderate water stress raise the question of the role of carbohydrate availability on plant growth under water deficit. In this paper, we addressed this question by analyzing how organs under moderate water stress partition their growth at a sub-daily time-scale. Plants experience a diurnal variation of carbon and water availability: during the night, metabolism relies on transitory pools of carbon such as starch, which set a metabolic limit to nighttime growth; these transitory pools are synthesized within the leaves in the daytime, during which transpiration competes with growth for water (Pantin et al., 2012). We thus took advantage of this daily fluctuations using two different systems and contrasting regimes of water and carbon availability. Firstly, we analyzed leaf growth at a day/night time-step in Arabidopsis mutants impaired in carbohydrate metabolism and grown under soil water deficit. Secondly, we studied the sub-hourly growth pattern of clementine fruits grown under various source-sink regimes and exposed to daily, natural fluctuations of air water deficit. Our results support the view that water deficits promote carbon satiation of sink organs and that the main effect of carbon availability on organ growth under moderate water deficits is through the supply of organic osmotica for turgor maintenance.

\section{MATERIALS AND METHODS DAY/NIGHT PATTERNS OF LEAF GROWTH IN Arabidopsis USING THE PHENOPSIS PLATFORM}

Arabidopsis thaliana plants were grown in soil at a 16 -h photoperiod $\left(\mathrm{PAR}=170 \mu \mathrm{mol} \mathrm{m} \mathrm{m}^{-2} \mathrm{~s}^{-1}\right.$ ) using the phenotyping platform PHENOPSIS, that allowed both precise control of the water content of each pot and imaging of the plant from the top
(Granier et al., 2006). The soil water content was maintained at a well-watered level of $0.40 \mathrm{~g}_{\text {water }} \mathrm{g}^{-1}$ dry soil (equivalent to a predawn water potential of $-0.2 \mathrm{MPa}$ ), the vapor pressure deficit (VPD) at $0.8 \mathrm{kPa}$, and the temperature at $20^{\circ} \mathrm{C}$. When plants reached the phenological stage 1.02 (Boyes et al., 2001), for half of the plants, irrigation was suspended until soil water content reached a target value corresponding to a moderate water stress $\left(0.23 g_{\text {water }}\right.$ $\mathrm{g}^{-1}$ dry soil, equivalent to a predawn water potential of $\left.-0.7 \mathrm{MPa}\right)$. Photographs taken at the end of each day and night, combined to a simplified version of the image analysis procedure described in Pantin et al. (2011), allowed us to monitor the day/night relative elongation rate of the sixth leaf during 8 days following leaf emergence, corresponding to the time at which this leaf reaches the half of its final size in the wild-type Col-0 under control conditions.

Both the wild-type accession Col- 0 and mutants affected in carbon metabolism were studied. These mutants were affected either in the daytime translocation of chloroplastic photosynthates $(t p t)$, in starch synthesis $(p g m)$, or in starch utilization at night (sexl, bam1, bam3, bam1 bam3, dpe1, mex1, dpe2). All mutants were in the Col-0 background. The genotypes are shown in Figure 1 at day 0 and day 7 following the emergence of the sixth leaf, in both well-watered and water stress conditions.

\section{DAILY PATTERNS OF FRUIT GROWTH IN CLEMENTINE USING DISPLACEMENT TRANSDUCERS IN THE FIELD}

We analyzed the growth pattern of clementine fruits in an experimental orchard during the 2008-2009 season. We used 18-year-old clementine trees (Citrus clementina Hort. ex Tan.) which were all clonal replicates grafted on Carrizo-citrange (Citrus sinensis [L.] Osbeck $\times$ Poncirus trifoliata Raf.) and grown

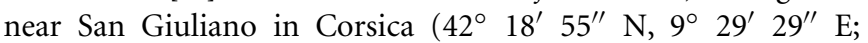
$51 \mathrm{~m}$ a.s.l.). Trees were about $2.5 \mathrm{~m}$ high, and were spaced at $4 \mathrm{~m} \times 6 \mathrm{~m}$. The plants were subjected to standard cultural practices for commercial clementine production. Fertilizers were supplied and insects and diseases controlled according to the recommendations of the local agriculture department. The trees were irrigated at full water requirements using micro-sprinklers under the canopy. Irrigation was scheduled based on evapotranspiration calculations estimated from the Penman-Monteith equation (Monteith, 1965) and from information supplied by the local weather station. Microclimate around the fruits was monitored using thermocouples, sensors measuring global solar irradiance (CES180, Cimel Electronique, Paris, France) and relative humidity sensors (HMP45C, Campbell, Scientific Inc., UT, USA). Climate data were stored every $15 \mathrm{~min}$. Fruit growth was monitored using displacement transducers recording variations in fruit diameter during 45 days between early September and late November 2008. Climate sensors and displacement transducers were connected to the same control box and data-logger (21X Micrologger, Campbell Scientific Inc., UT, USA), allowing simultaneous measurements for growth and climate every $15 \mathrm{~min}$.

To modify the carbon availability for the growing fruits, a defoliation treatment was applied on selected fruiting branches in order to modify the leaf-to-fruit ratio. During the flowering period, the plants were isolated from pollinators to prevent cross-pollination and seed production. Only fully expanded flowers from May 5th 


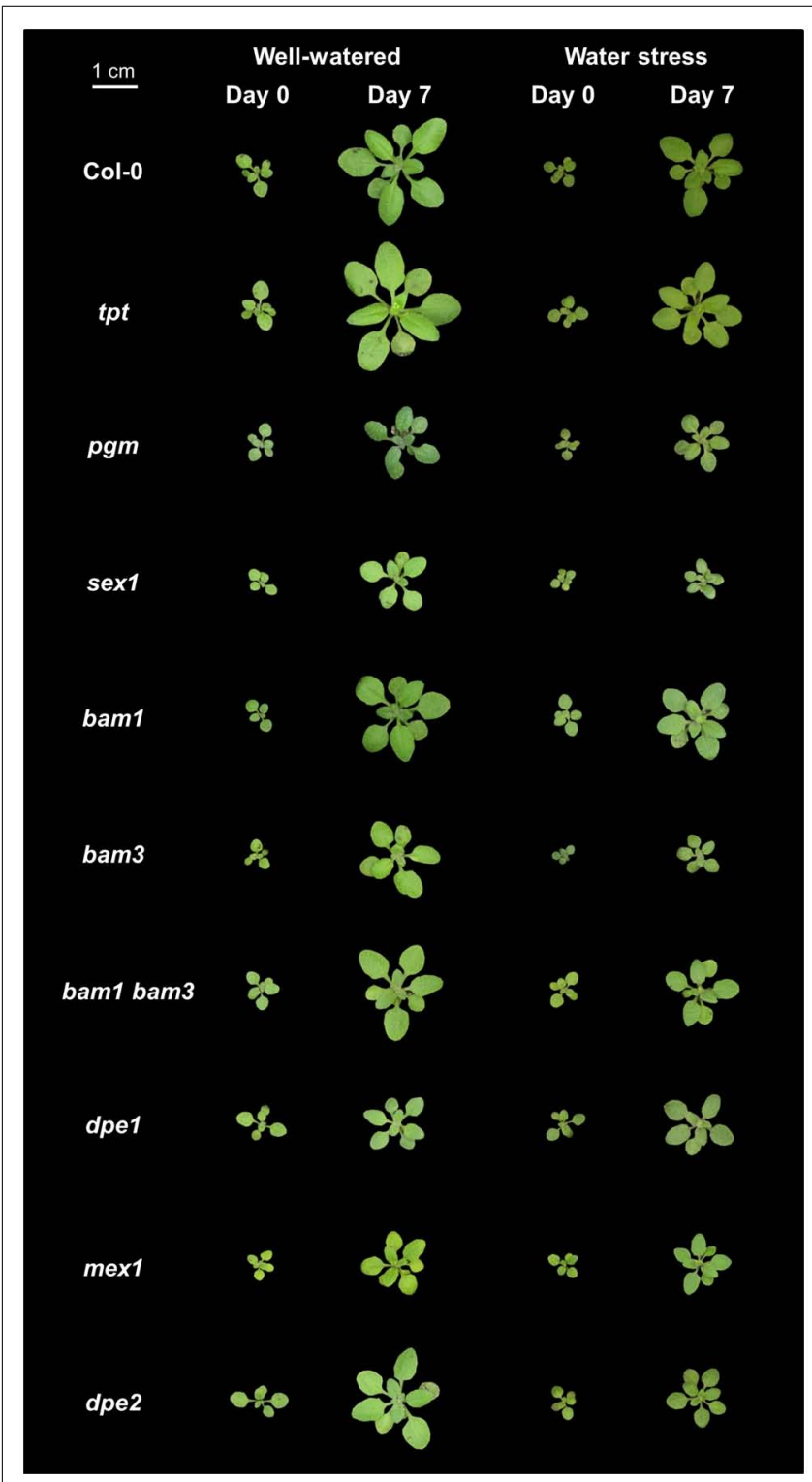

FIGURE 1 | Photographs of representative plants of Arabidopsis mutants affected in carbon metabolism grown in well-watered conditions or under soil water stress. The wild-type Col-0 is shown at day 0 and day 7 following emergence of the sixth leaf in well-watered conditions or under moderate water stress (predawn water potential of $-0.7 \mathrm{MPa})$, together with a mutant affected in the daytime translocation of chloroplastic photosynthates (tpt), starch metabolism (pgm), or starch utilization at night (sex1, bam1, bam3, bam1 bam3, dpe1, mex1, dpe2).

to May 15th 2008 were selected to obtain fruits of similar age. After the completion of cell division in the fruit (at the end of July under Mediterranean climate; Tadeo et al., 2008), the leaf-to-fruit ratio was set to 30,15 , or 5 leaves per fruit to obtain a control, moderate or low carbon availability (Poiroux-Gonord et al., 2013). The 120 selected fruiting branches were composed of 1-year shoots from the spring flush of the previous season. Fruiting branches were chosen among the trees as having similar initial stem diameter (about $1 \mathrm{~cm}$ ), height above ground (about $1.5 \mathrm{~m}$ ), and exposure to light in East orientation. Before the defoliation treatment, girdling was applied on shoots with at least 30 leaves in July, after fruit set. Girdling consisted of removing a $10 \mathrm{~mm}$-wide band of bark in the middle of the main stem of each selected branch to prevent any movement of assimilates between the fruiting branch and the rest of the tree. Leaves were all fully expanded at the time of girdling. Fruit growth was monitored on at least three fruits per level of leaf-to-fruit ratio. Displacement transducers were also placed on three peeled fruits from girdled fruiting branches with 30 leaves.

The fresh and dry weight of the pulp and the peel were recorded regularly from September to March, together with glucose, fructose, and sucrose contents of the pulp. Immediately after harvest, fruits peel and pulp were weighed separately for fresh mass determination. Aliquots were lyophilized for dry mass measurements and sugar analyzes. Then, the pulp material was ground to a fine powder and stored at $-80^{\circ} \mathrm{C}$ for subsequent analyzes. Sugar analyzes of the pulp were performed by HPLC according to the method previously described in Poiroux-Gonord et al. (2013).

\section{STATISTICAL ANALYZES}

All graphics and statistical analyzes were performed with the $\mathrm{R}$ software (R Development Core Team, 2012).

To analyze the day/night pattern of relative elongation rate of the sixth leaf in the ten Arabidopsis genotypes under wellwatered conditions and under water stress, a heat map was performed as follows. For each genotype $\times$ environment combination, the difference between nighttime- and daytime-mean relative elongation rate was computed at each of the 8 days after leaf emergence, and assigned to a color between green

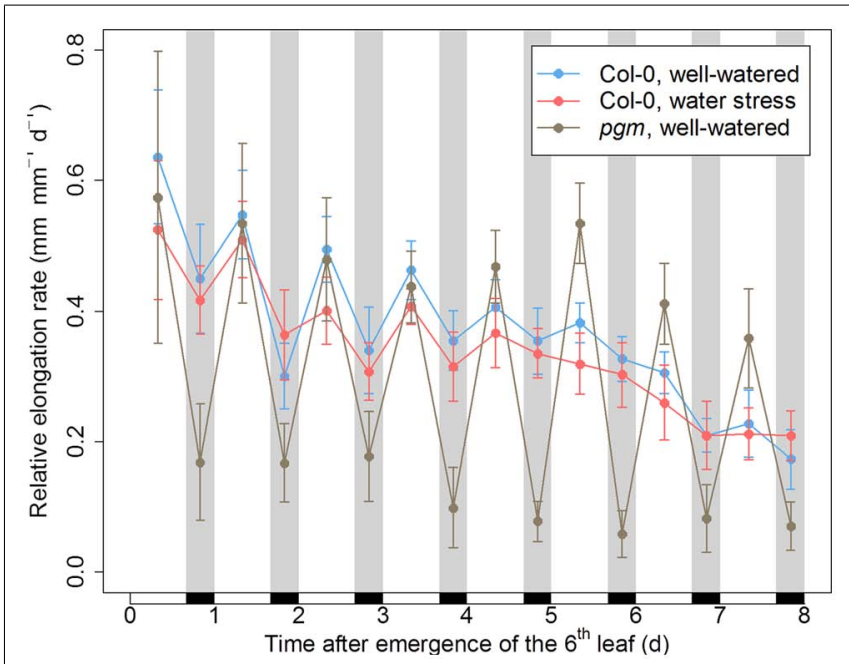

FIGURE 2 | Day/night pattern of leaf growth in Arabidopsis plants with a disturbed hydraulic or metabolic status. The relative elongation rate of the sixth leaf was monitored for 8 days following its emergence in the wild-type Col-0 under well-watered conditions or under moderate soil water stress (predawn water potential of $-0.7 \mathrm{MPa}$ ), as well as in the starchless mutant pgm under well-watered conditions. Black rectangles and gray bands indicate the night periods. Error bars are 95\% confidence intervals. 
(daytime growth) and red (nighttime growth). A hierarchical clustering of the kinetics was then performed using the Euclidean distances. The original daytime and nighttime values were further detailed for the days 4-6 following leaf emergence, as a bar plot showing the means and the $95 \%$ confidence intervals.

To analyze the effect of the natural variations in VPD on clementine fruit growth, we took advantage of the natural variability in the daily patterns of VPD collected throughout the experiment, which were highly variable from day to day. Each day starting at 00:00 and ending at 23:59 was considered as an individual with 96 variables, corresponding to the VPD collected every 15 min. A k-means clustering analysis was performed on these climate data, which allowed to statistically allocate the days according to their similarity in VPD. Three clusters were obtained, equivalent to a day with high (the daily maximal value of VPD, $\left.\mathrm{VPD}_{\max }>1 \mathrm{kPa}\right)$, moderate $\left(0.5 \mathrm{kPa}<\mathrm{VPD}_{\max }<1 \mathrm{kPa}\right)$, and low VPD $\left(\mathrm{VPD}_{\max }<0.5 \mathrm{kPa}\right)$, respectively. The fruit growth patterns (as well as PAR measurements) were then affected to one of these three clusters according to the day they were collected, and were averaged within each cluster on a $15 \mathrm{~min}$ basis.

\section{RESULTS AND DISCUSSION GROWTH LIMITATION UNDER SOIL WATER DEFICIT: INSIGHTS FROM Arabidopsis LEAVES \\ Growth of young leaves is driven by carbon availability in well-watered conditions}

To analyze the impact of the day/night regime on leaf growth, we monitored the elongation rate of the sixth leaf in Arabidopsis plants during the first 8 days and nights following its emergence. In the wild-type Col-0, nocturnal depressions of growth were observed early after leaf emergence, but progressively vanished during leaf development (Figure 2). In Arabidopsis leaves, metabolic demand at night is sustained by the transitory starch synthesized in the daytime, a period during which stomatal transpiration reduces water availability. Accordingly, using developmental patterns of leaf relative expansion rate collected on several Arabidopsis genotypes grown under different environmental conditions, we showed

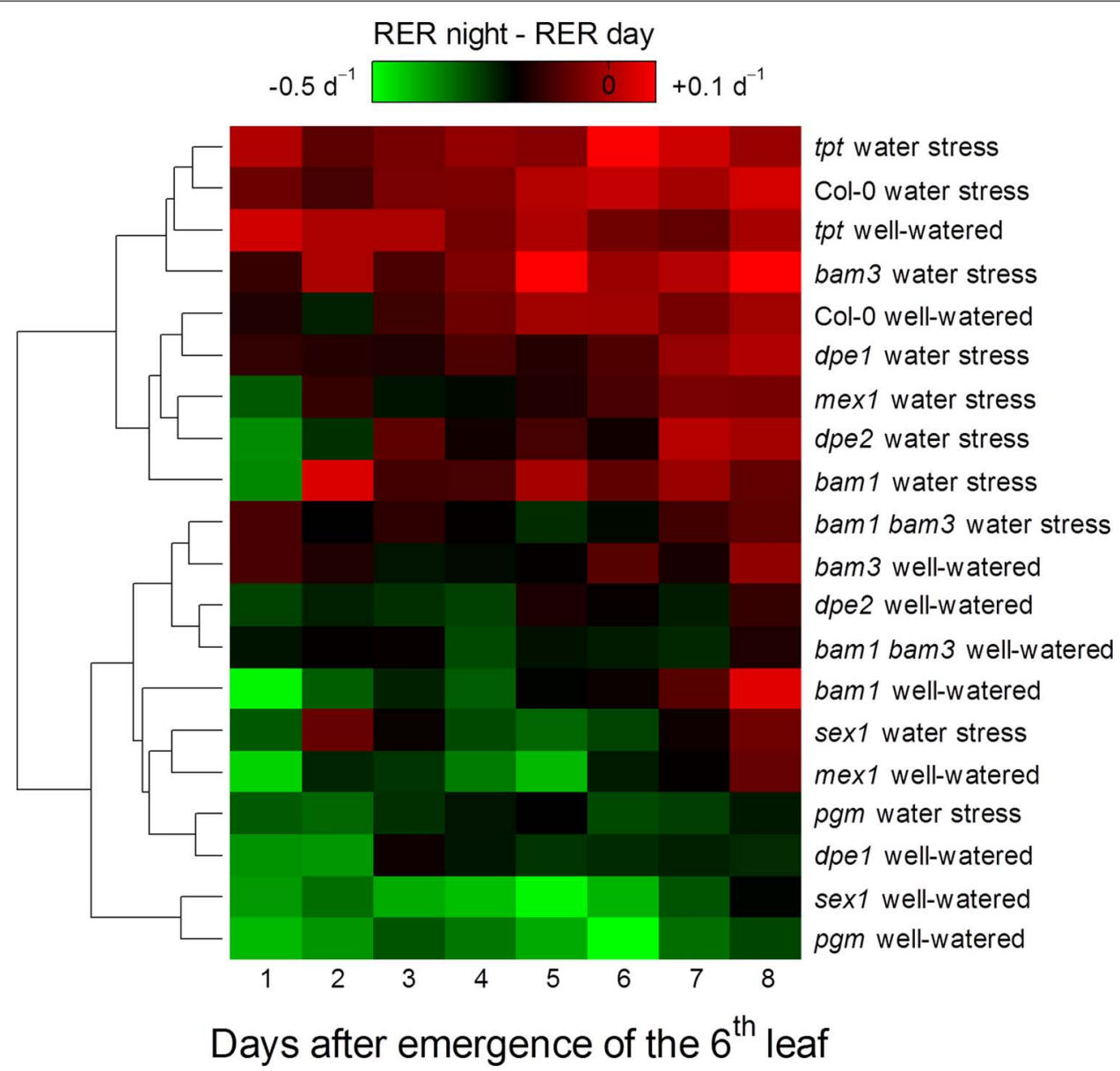

FIGURE 3 | Heat map of the day/night patterns of leaf growth in Arabidopsis mutants affected in carbon metabolism and grown in well-watered conditions or under moderate soil water stress. The dendrogram represents a hierarchical clustering analysis (Euclidean distances) of the difference between nighttime and daytime relative elongation rate of the sixth leaf during 8 days following its emergence. The difference was associated to a color, with closeness to green indicating growth preferentially in the daytime and closeness to red indicating growth preferentially in the nighttime. Note that moderate soil water stress increases nighttime growth relative to daytime growth in all genotypes. 
previously that nighttime depressions of growth are associated to a metabolic limitation, while daytime depressions of growth are related to a hydraulic limitation (Pantin et al., 2011). Thus, the result shown in Figure 2 are consistent with the idea that a metabolic limitation exerting on leaf growth at night is progressively released as the leaf switches from sink to source (Pantin et al., 2011).

To study how a perturbation in carbon availability may affect leaf growth, we analyzed the leaf growth pattern in several mutants affected in starch metabolism or in photosynthate translocation. Photographs of these mutants are shown in Figure 1. For all genotypes, the difference between nighttime and daytime relative elongation rate during leaf development is presented in Figure 3 as a heat map. The genotypes were then ranked according to a clustering analysis performed on these day/night variations of elongation. The daytime and nighttime leaf elongation observed during the days 4, 5, and 6 following emergence of the sixth leaf were also averaged and presented in Figure 4.

In well-watered conditions, the night reduction of elongation of the tpt mutant in the early stages was less than in the wild-type (Figure 3), as already observed in potato (Kehr et al., 1998). This is consistent with the mutant's impairment in the daytime translocation of chloroplastic photosynthates, which affects daytime carbon availability but increases starch synthesis (Schneider et al., 2002; Cho et al., 2011). Conversely, all mutants affected in nighttime carbon availability (i.e., through an impaired starch synthesis or breakdown) showed marked depressions of growth in the nighttime, as illustrated with $p g m$ in Figure 2 and with all genotypes in Figures 3 and 4. Compared to the wild-type, these nocturnal depressions were both amplified in magnitude and extended to later stages of leaf development. The most severe phenotype was observed in pgm and sex1, namely the genotypes of our list which were affected the most upstream in the starch metabolism pathway, and which were the most dramatically impaired in starch turnover (Zeeman et al., 2010; Stitt and Zeeman, 2012). The other starch mutants, dpe1, dpe2, mex1, bam1, bam3, and the bam1 bam3 double mutant, clustered closely together and showed a less extreme phenotype than $p g m$ or sex1 (Figure 3). Overall, this ranking of mutants was in agreement with their intermediate impairment in starch degradation (Critchley et al., 2001; Messerli et al., 2007; Fulton et al., 2008), though bam1 was not expected to have a phenotype distinct from the wild-type since this mutant has a normal day/night pattern of starch turnover and that BAM1 is presumably active in guard cells during the daytime (Fulton et al., 2008; Valerio et al., 2011). It may be argued that this classification could be biased by an extended duration of leaf growth in these mutants. However, a similar classification of starch mutants was obtained in Pantin et al. (2011), where the growth patterns were normalized according to the duration of development. Thus, in well-watered conditions, the day/night pattern of leaf growth was globally dictated by the severity of the impairment in daytime or nighttime carbohydrate availability.

\section{Soil water deficit releases the metabolic limitation on leaf growth}

When Col-0 plants were grown under moderate soil water stress, shoot area decreased (Figure 1). Elongation of the sixth leaf decreased especially in the daytime (Figure 2), although this effect was less significant than in Pantin et al. (2011) due to the higher

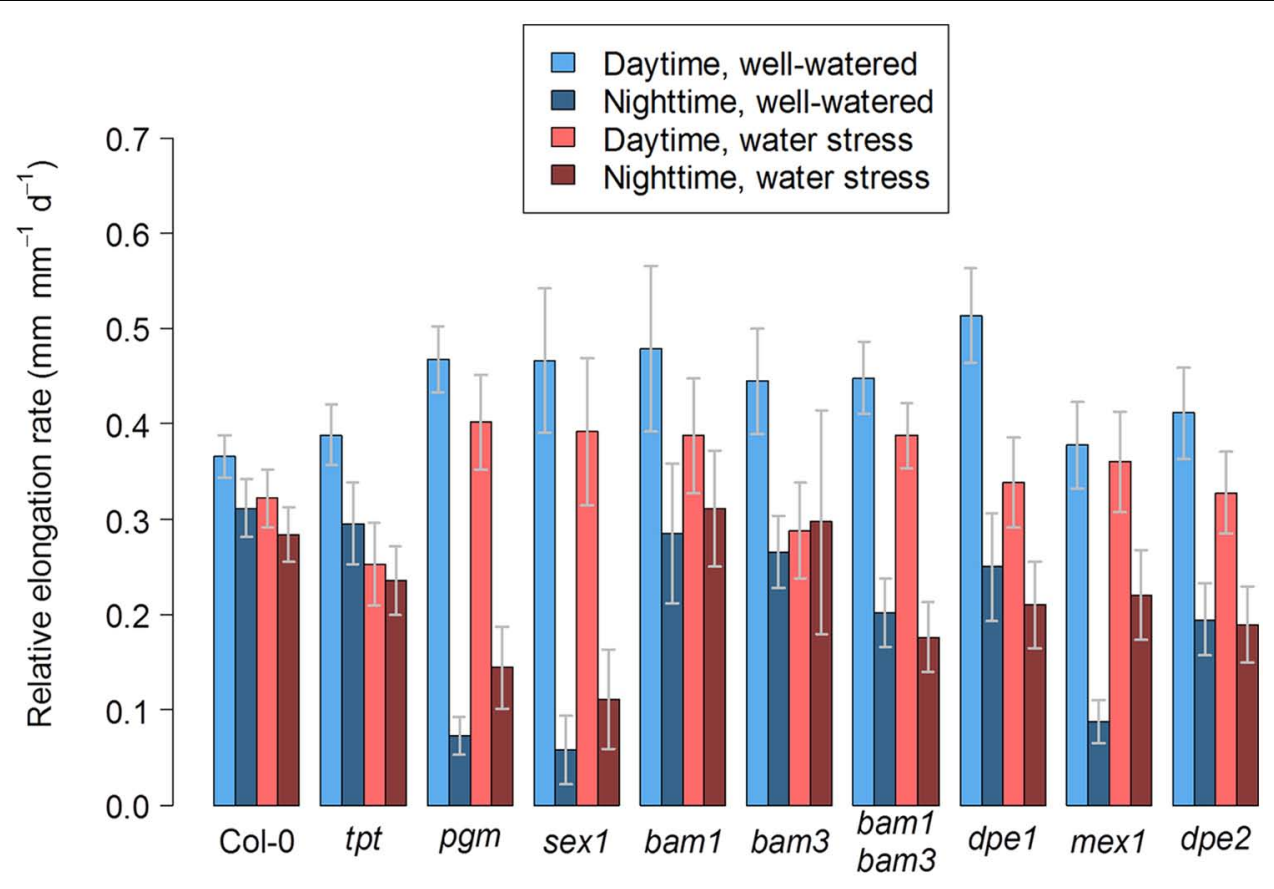

FIGURE 4 | Day/night leaf growth in Arabidopsis mutants affected in carbon metabolism and grown in well-watered conditions or under soil water stress. The bar plot shows the daytime and nighttime growth averaged for the days 4, 5, and 6 following emergence of the sixth leaf under well-watered conditions or under moderate soil water stress. Error bars are 95\% confidence intervals. 
evaporative demand prevailing in the growth chamber used in the latter study. Strikingly, under water stress, all mutants affected in nighttime carbon availability increased nighttime growth relative to daytime growth (Figure 3). This was achieved by maintaining (dpe1, dpe2, bam1, bam3, bam1 bam3) or even increasing (pgm, sex1, mex1) nighttime growth rates while decreasing daytime growth rates (Figure 4). As a consequence, water-stressed pgm and sexl clustered with the well-watered genotypes less affected in nighttime carbon availability, while the latter genotypes under water stress tended to cluster closer to the wild-type (Figure 3). This result indicates that water stress partly releases the carbon limitation on leaf growth that these mutations generate under well-watered conditions, either by providing structural growth with molecular bricks or by fuelling expansive growth with osmotica.

This result also shows that the accumulation of carbohydrates observed under moderate water stress (e.g., Hummel et al., 2010) in the wild-type does not translate into additional growth as it does in the starch mutants at night. It could be argued that carbohydrates are not available for structural growth if sequestered in the vacuole for osmotic purposes, thereby generating a metabolic limitation under water stress in the wild-type. However, in the model plant Arabidopsis under moderate water deficit, osmotic adjustment mobilizes only a minor part of the daily carbohydrate balance, which was largely in excess due to reduced growth but maintained photosynthesis (Hummel et al., 2010). Thus, our results support the conclusion that the reduction of leaf growth observed in wild-type plants under moderate water stress does not arise from carbon starvation; by contrast, moderate water deficits induce carbon satiation.

\section{GROWTH LIMITATION UNDER ATMOSPHERIC WATER DEFICIT: INSIGHTS FROM CLEMENTINE FRUITS \\ Carbon availability positively affects fruit growth and sugar contents}

To further investigate the role of carbon availability on growth of organs when exposed to moderate water deficit, we analyzed the growth pattern of clementine fruits with contrasting leaf-to-fruit ratio $(30,15$, or 5$)$ in an experimental orchard, namely in field conditions. Trees were all well-watered and fertilized.

Carbon availability accelerated the onset of fruit color change (Figure 5), consistent with the idea that sugar availability promotes fruit ripening (Fanciullino et al., 2013). In the three treatments, full expansion and maturity were reached in the middle of December, as indicated by the plateau of fresh and dry weight, as well as sugar content (Figure 6). At later stages, these variables showed a moderate tendency to decrease, indicating over-maturity. These patterns are consistent with data from previous studies on clementine fruits growing under Mediterranean climate (Cercós et al., 2006; Tadeo et al., 2008). Whereas the defoliation treatment (performed in July) did not affect the seasonal pattern of fruit growth, it strongly affected fruit weight at maturity. For the 5 leaves per fruit treatment, a decrease of about 60 and 50\% was observed in the pulp and peel fresh mass, respectively, when compared to the control. A less severe treatment also affected fruit mass, since a reduction in fresh mass up to $40 \%$ for both the pulp and the peel was observed at 15 leaves per fruit, when compared to the

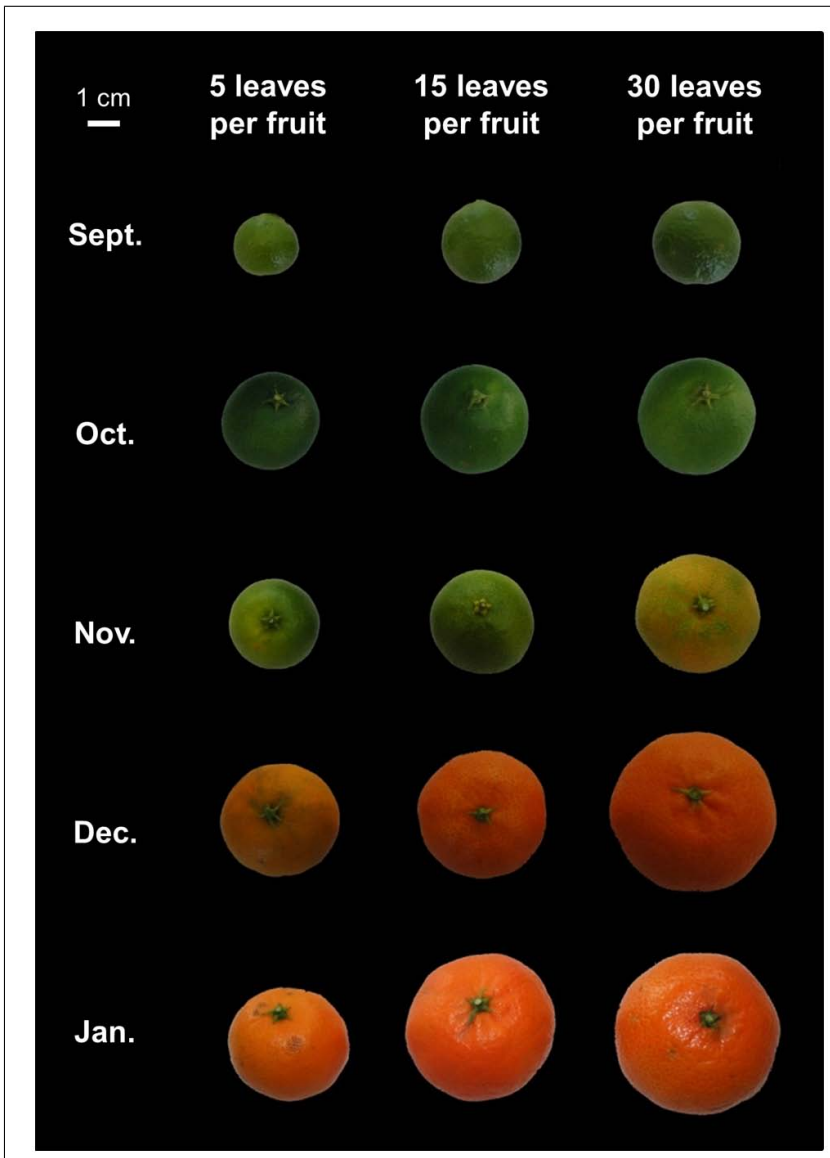

FIGURE 5 | Photographs of representative clementine fruits from fruiting branches bearing $\mathbf{5 , 1 5}$, or $\mathbf{3 0}$ leaves. The pictures illustrate the effects of carbon availability on fruit growth and maturity. A low carbon supply (five leaves per fruit) reduced fruit diameter and induced a delay in fruit ripening.

control. The fruit dry mass followed similar trends. The defoliation treatment also modified soluble sugar contents in pulp (Figure 6). The changes in soluble sugars were mainly due to variations in sucrose concentrations. The largest decrease in sucrose was observed for the five leaves per fruit treatment in November, with a reduction of $80 \%$ when expressed on a fresh weight basis.

The strong, positive impact of the leaf-to-fruit ratio on fruit weight and sugar contents indicates that fruit growth is positively controlled by carbon availability, as repeatedly observed in other tree species (e.g., Berman and DeJong, 1996, on peach; Léchaudel et al., 2007, on mango). These results are consistent with the fruit as a sink organ relying on proximal leaves for its supply with photoassimilates.

\section{Atmospheric water deficit highlights the osmotic role of photoassimilates on fruit growth}

To evaluate how moderate water deficit may affect the relationship between fruit growth and carbon availability, we took advantage of the daily, natural fluctuations in the VPD of the atmosphere. Daily growth variations were monitored in fruits at the three levels 


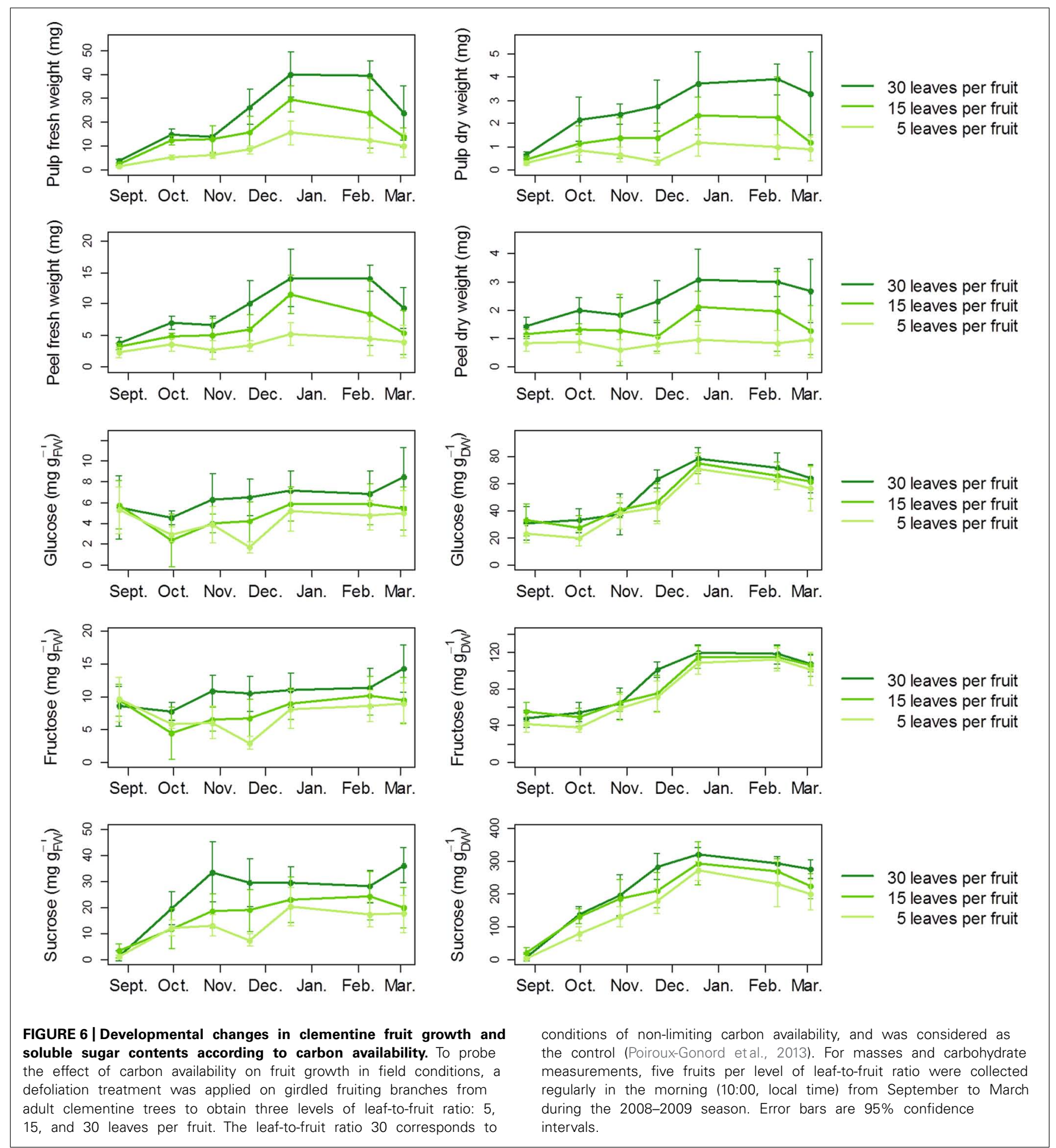

of carbon availability previously described. In addition, growth was monitored on fruits which were carefully peeled and grown at high carbon availability, in order to increase fruit exposure to evaporative demand. Our growth analysis covered 45 days between early September and late November. Throughout this period, daily patterns of VPD were highly variable from day to day, exhibiting a peak at midday during the driest days, and remaining almost constant during the wettest days. A k-means clustering analysis was performed to partition the days according to their similarity in VPD and three clusters were obtained gathering days with the highest $\left(\mathrm{VPD}_{\max }>1 \mathrm{kPa}\right)$, intermediate $\left(1 \mathrm{kPa}<\mathrm{VPD}_{\max }<0.5 \mathrm{kPa}\right)$, and lowest $\mathrm{VPD}\left(\mathrm{VPD}_{\max }<0.5 \mathrm{kPa}\right)$, respectively. The fruit growth patterns were then averaged within each of these three clusters (Figure 7). 
Consistent with the negative effect of VPD on fruit water potential, strong, negative depressions of fruit growth were observed at high VPD whatever the leaf-to-fruit ratio. Negative expansive growth is typically due to a water loss that leads to fruit shrinkage (Fishman and Génard, 1998). The strongest depressions of growth were observed in the peeled fruits even though they were associated with the high leaf-to-fruit ratio, suggesting a prevailing hydraulic origin of these depressions. Furthermore, these depressions were attenuated at moderate VPD and completely abolished at low VPD. After these brutal depressions, fruit diameter progressively recovered from ca. 11:00 in the morning, and diameter variation became positive again $3 \mathrm{~h}$ later. This rapid recovery was probably due to either a midday depression of stomatal conductance (Hu et al., 2009), a rapid osmotic adjustment permitted either by newly synthesized photoassimilates or by ion uptake from the cell wall (Thorpe et al., 1993), or a rapid softening of cell walls (Bogoslavsky and Neumann, 1998). Remarkably, the strongest depressions of fruit growth were observed during the periods of highest irradiance, which co-occurred with the periods of highest VPD (Figure 7). This result suggests that, at least on the short-term, the negative effect of evaporative demand on fruit growth dominates over the positive effect of irradiance.

Interestingly, a high leaf-to-fruit ratio reduced the maximum fruit shrinkage. Moreover, this effect was clearly visible at high VPD, but was strongly reduced at intermediate VPD and no longer visible at low VPD (Figure 7). An explanation for the positive effect of carbon availability on preventing fruit shrinkage under atmospheric water deficit is that higher concentrations of photoassimilates contribute to lower osmotic potential and reduce water loss. Such a hypothesis is supported by literature data. In peach fruit, a high leaf-to-fruit ratio increased the osmotic pressure of the fruit and reduced the transpiration-induced fruit shrinkage, either during experiments (McFadyen et al., 1996) or in silico using a biophysical model of fruit growth (Fishman and Génard, 1998). In line with this, although pulp sugar contents were relatively unaffected by the leaf-to-fruit ratio when expressed per unit of dry weight, they were clearly increased by a high leaf-to-fruit ratio when expressed per unit of fresh weight, i.e., when considered as solutes (Figure 6). These concentrations were high enough to postulate an osmotic effect. Thus, our results suggest that the positive effect of carbon availability on short-term fruit growth under air
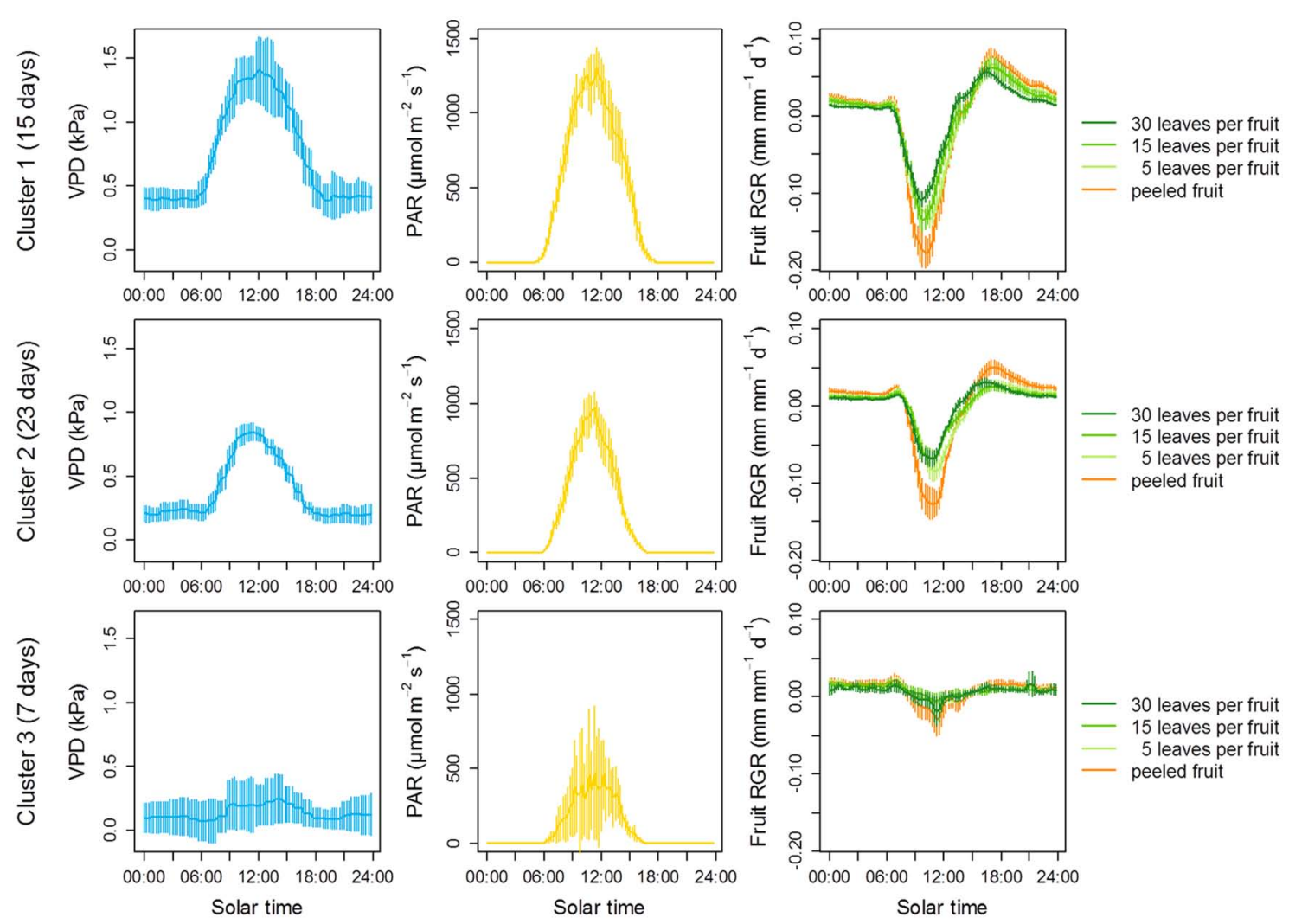

FIGURE 7 |The relationship between carbon availability and fruit growth is conditional on atmospheric water stress in clementine. Fruit growth was monitored using displacement transducers on at least three fruits per level of leaf-to-fruit ratio during 45 days between early September and late November. Some displacement transducers were also placed on peeled fruits from girdled fruiting branches with 30 leaves. Climate data (air humidity, temperature and irradiance) were collected every 15 min together with changes in fruit diameter. A k-means clustering was performed to group days of the experiment on the basis of their similarity in VPD. Three clusters were statistically obtained, equivalent to days with a dry (top), intermediate (middle), and wet (bottom) atmosphere. Irradiance as well as fruit growth was then averaged according to these three clusters. Error bars are $95 \%$ confidence intervals. 
water deficit is not linked to a limitation of structural growth by carbon under these conditions but rather the result of a soluble carbohydrate-induced lower osmotic potential which buffers the variations in fruit diameter generated by the fluctuations in water potential.

\section{CONCLUSION}

Increases in carbohydrate concentration following moderate water stress raise the question of the role of carbohydrate availability on plant growth under water deficit. In this study, we addressed this question using two different species under either soil or air water deficits. In growing Arabidopsis leaves, soil water deficit induces an accumulation of carbohydrates which contributes to shift growth during the nighttime, a period when water balance is much less affected by transpiration. In mutants impaired in starch metabolism, growth at night is even promoted by water deficit, suggesting that water stress induces carbon satiation in these growing leaves. In clementine fruits, atmospheric water stress-induced depressions of growth are of hydraulic nature and deepen during dry days despite higher irradiance. A high carbohydrate status reduces these depressions, suggesting that photoassimilates are rapidly mobilized and used as osmotica to buffer turgor pressure against the variations in fruit water balance. These two rather different systems illustrate that plants under moderate water stress do not suffer from carbon starvation which would impair structural growth, but instead make an efficient use of their carbohydrates to buffer expansive growth variations against the environmental fluctuations in water availability.

\section{ACKNOWLEDGMENTS}

We thank Alexis Bédiée, Coline Blanchard, Gaëlle Rolland, Isabelle Poggi, and Jérôme Barbaggio for their technical support. We are grateful to Samuel Zeeman for both the gift of the starch mutants and his very useful comments on the manuscript. This work was supported by the French Ministry of Research (PhD fellowship to Florent Pantin), the Collectivité Territoriale de Corse (postdoctoral fellowship to Anne-Laure Fanciullino), and the European Commission through the FP6 AGRONOMICS Integrated Project (grant no. LSHG-CT-2006-037704 to Bertrand Muller and postdoctoral fellowship to Catherine Massonnet).

\section{AUTHOR CONTRIBUTIONS}

All authors designed and performed the experiments. Florent Pantin, Anne-Laure Fanciullino, Catherine Massonnet, and Bertrand Muller wrote the manuscript.

\section{REFERENCES}

Andriotis, V. M. E., Pike, M. J., Schwarz, S. L., Rawsthorne, S., Wang, T. L., and Smith, A. M. (2012). Altered starch turnover in the maternal plant has major effects on Arabidopsis fruit growth and seed composition. Plant Physiol. 160, 1175-1186. doi: 10.1104/pp.112.205062

Berman, M. E., and DeJong, T. M. (1996). Water stress and crop load effects on fruit fresh and dry weights in peach (Prunus persica). Tree Physiol. 16, 859-864. doi: 10.1093/treephys/16.10.859

Bidel, L. P. R., Renault, P., Pagès, L., and Rivière, L. M. (2000). Mapping meristem respiration of Prunus persica (L.) Batsch seedlings: potential respiration of the meristems, $\mathrm{O}_{2}$ diffusional constraints and combined effects on root growth. $J$. Exp. Bot. 51, 755-768. doi: 10.1093/jexbot/51.345.755
Bogeat-Triboulot, M. B., Brosche, M., Renaut, J., Jouve, L., Le Thiec, D., Fayyaz, P., et al. (2007). Gradual soil water depletion results in reversible changes of gene expression, protein profiles, ecophysiology, and growth performance in Populus euphratica, a poplar growing in arid regions. Plant Physiol. 143, 876-892. doi: 10.1104/pp.106.088708

Bogoslavsky, L., and Neumann, P. M. (1998). Rapid regulation by acid pH of cell wall adjustment and leaf growth in maize plants responding to reversal of water stress. Plant Physiol. 118, 701-709. doi: 10.1104/pp.118.2.701

Boyer, J. S. (1970). Leaf enlargement and metabolic rates in corn, soybean, and sunflower at various leaf water potentials. Plant Physiol. 46, 233-235. doi: 10.1104/pp.46.2.233

Boyer, J. S. (1982). Plant productivity and environment. Science 218, 443-448. doi: 10.1126/science.218.4571.443

Boyes, D. C., Zayed, A. M., Ascenzi, R., McCaskill, A. J., Hoffman, N. E., Davis, K. R., et al. (2001). Growth stage-based phenotypic analysis of Arabidopsis: a model for high throughput functional genomics in plants. Plant Cell 13, 1499-1510. doi: 10.1105/TPC.010011

Cercós, M., Soler, G., Iglesias, D. J., Gadea, J., Forment, J., and Talón, M. (2006). Global analysis of gene expression during development and ripening of citrus fruit flesh. A proposed mechanism for citric acid utilization. Plant Mol. Biol. 62, 513-527. doi: 10.1007/s11103-006-9037-7

Cho, M.-H., Lim, H., Shin, D. H., Jeon, J.-S., Bhoo, S. H., Park, Y.-I., et al. (2011). Role of the plastidic glucose translocator in the export of starch degradation products from the chloroplasts in Arabidopsis thaliana. New Phytol. 190, 101-112. doi: 10.1111/j.1469-8137.2010.03580.x

Cosgrove, D. J. (1993). Wall extensibility: its nature, measurement and relationship to plant cell growth. New Phytol. 124, 1-23. doi: 10.1111/j.14698137.1993.tb03795.x

Critchley, J. H., Zeeman, S. C., Takaha, T., Smith, A. M., and Smith, S. M. (2001). A critical role for disproportionating enzyme in starch breakdown is revealed by a knock-out mutation in Arabidopsis. Plant J. 26, 89-100. doi: 10.1046/j.1365313x.2001.01012.x

Dosio, G. A. A., Tardieu, F., and Turc, O. (2011). Floret initiation, tissue expansion and carbon availability at the meristem of the sunflower capitulum as affected by water or light deficits. New Phytol. 189, 94-105. doi: 10.1111/j.1469-8137.2010.03445.x

Fan, L., Linker, R., Gepstein, S., Tanimoto, E., Yamamoto, R., and Neumann, P. M. (2006). Progressive inhibition by water deficit of cell wall extensibility and growth along the elongation zone of maize roots is related to increased lignin metabolism and progressive stelar accumulation of wall phenolics. Plant Physiol. 140, 603-612. doi: 10.1104/pp.105.073130

Fanciullino, A.-L., Bidel, L. P. R., and Urban, L. (2013). Carotenoid responses to environmental stimuli: integrating redox and carbon controls into a fruit model. Plant Cell Environ. doi: 10.1111/pce.12153 [Epub ahead of print].

Fishman, S., and Génard, M. (1998). A biophysical model of fruit growth: simulation of seasonal and diurnal dynamics of mass. Plant Cell Environ. 21, 739-752. doi: 10.1046/j.1365-3040.1998.00322.x

Flexas, J., Bota, J., Loreto, F., Cornic, G., and Sharkey, T. D. (2004). Diffusive and metabolic limitations to photosynthesis under drought and salinity in C3 Plants. Plant Biol. 6, 269-279. doi: 10.1055/s-2004-820867

Freixes, S., Thibaud, M.-C., Tardieu, F., and Muller, B. (2002). Root elongation and branching is related to local hexose concentration in Arabidopsis thaliana seedlings. Plant Cell Environ. 25, 1357-1366. doi: 10.1046/j.13653040.2002.00912.x

Fulton, D. C., Stettler, M., Mettler, T., Vaughan, C. K., Li, J., Francisco, P., et al. (2008). $\beta$-AMYLASE4, a noncatalytic protein required for starch breakdown, acts upstream of three active $\beta$-amylases in Arabidopsis chloroplasts. Plant Cell 20, 1040-1058. doi: 10.1105/tpc.107.056507

Génard, M., Lescourret, F., Ben Mimoun, M., Besset, J., and Bussi, C. (1998). A simulation model of growth at the shoot-bearing fruit level. II. Test and effect of source and sink factors in the case of peach. Eur. J. Agron. 9, 189-202. doi: 10.1016/S1161-0301(98)00036-7

Gibon, Y., Pyl, E.-T., Sulpice, R., Lunn, J. E., Höhne, M., Günther, M., et al. (2009). Adjustment of growth, starch turnover, protein content and central metabolism to a decrease of the carbon supply when Arabidopsis is grown in very short photoperiods. Plant Cell Environ. 32, 859-874. doi: 10.1111/j.1365-3040.2009.01965.x 
Granier, C., Aguirrezábal, L., Chenu, K., Cookson, S. J., Dauzat, M., Hamard, P., et al. (2006). PHENOPSIS, an automated platform for reproducible phenotyping of plant responses to soil water deficit in Arabidopsis thaliana permitted the identification of an accession with low sensitivity to soil water deficit. New Phytol. 169, 623-635. doi: 10.1111/j.1469-8137.2005.01609.x

Hsiao, T. C. (1973). Plant responses to water stress. Annu. Rev. Plant Physiol. 24, 519-570. doi: 10.1146/annurev.pp.24.060173.002511

Hu, M.-J., Guo, Y.-P., Shen, Y.-G., Guo, D.-P., and Li, D.-Y. (2009). Midday depression of photosynthesis and effects of mist spray in citrus. Ann. Appl. Biol. 154, 143-155. doi: 10.1111/j.1744-7348.2008.00282.x

Hummel, I., Pantin, F., Sulpice, R., Piques, M., Rolland, G., Dauzat, M., et al (2010). Arabidopsis plants acclimate to water deficit at low cost through changes of carbon usage: an integrated perspective using growth, metabolite, enzyme, and gene expression analysis. Plant Physiol. 154, 357-372. doi: 10.1104/pp.110. 157008

Kaiser, W. M. (1987). Effects of water deficit on photosynthetic capacity. Physiol. Plant. 71, 142-149. doi: 10.1111/j.1399-3054.1987.tb04631.x

Kehr, J., Hustiak, F., Walz, C., Willmitzer, L., and Fisahn, J. (1998). Transgenic plants changed in carbon allocation pattern display a shift in diurnal growth pattern. Plant J. 16, 497-503. doi: 10.1046/j.1365-313x.1998.00318.x

Léchaudel, M., Génard, M., Lescourret, F., Urban, L., and Jannoyer, M. (2005) Modeling effects of weather and source-sink relationships on mango fruit growth. Tree Physiol. 25, 583-597. doi: 10.1093/treephys/25.5.583

Léchaudel, M., Vercambre, G., Lescourret, F., Normand, F., and Génard, M. (2007). An analysis of elastic and plastic fruit growth of mango in response to various assimilate supplies. Tree Physiol. 27, 219-230. doi: 10.1093/treephys/27. 2.219

Lescourret, F., Ben Mimoun, M., and Génard, M. (1998). A simulation model of growth at the shoot-bearing fruit level. I. Description and parameterization for peach. Eur. J. Agron. 9, 173-188. doi: 10.1016/S1161-0301(98)00035-5

Lockhart, J. A. (1965). An analysis of irreversible plant cell elongation. J. Theor. Biol. 8, 264-275. doi: 10.1016/0022-5193(65)90077-9

McDowell, N. G. (2011). Mechanisms linking drought, hydraulics, carbon metabolism, and vegetation mortality. Plant Physiol. 155, 1051-1059. doi: 10.1104/pp.110.170704

McDowell, N. G., Pockman, W. T., Allen, C. D., Breshears, D. D., Cobb, N., Kolb, T., et al. (2008). Mechanisms of plant survival and mortality during drought: why do some plants survive while others succumb to drought? New Phytol. 178, 719-739. doi: 10.1111/j.1469-8137.2008.02436.x

McFadyen, L. M., Hutton, R. J., and Barlow, E. W. R. (1996). Effects of crop load on fruit water relations and fruit growth in peach. J. Hortic. Sci. 71, 469-480.

Messerli, G., Nia, V. P., Trevisan, M., Kolbe, A., Schauer, N., Geigenberger, P., et al. (2007). Rapid classification of phenotypic mutants of Arabidopsis via metabolite fingerprinting. Plant Physiol. 143, 1484-1492. doi: 10.1104/pp.106.090795

Monteith, J. L. (1965). Evaporation and environment. Symp. Soc. Exp. Biol. 19, 205-234.

Muller, B., Pantin, F., Génard, M., Turc, O., Freixes, S., Piques, M., et al. (2011). Water deficits uncouple growth from photosynthesis, increase $\mathrm{C}$ content, and modify the relationships between $\mathrm{C}$ and growth in sink organs. J. Exp. Bot. 62 1715-1729. doi: 10.1093/jxb/erq438

Muller, B., Reymond, M., and Tardieu, F. (2001). The elongation rate at the base of maize leaf shows an invariant pattern during both the steady-state elongation and the establishment of the elongation zone. J. Exp. Bot. 52, 1259-1268. doi 10.1093/jexbot/52.359.1259

Pantin, F., Monnet, F., Jannaud, D., Costa, J. M., Renaud, J., Muller, B., et al. (2013). The dual effect of abscisic acid on stomata. New Phytol. 197, 65-72. doi: $10.1111 /$ nph.12013

Pantin, F., Simonneau, T., and Muller, B. (2012). Coming of leaf age: control of growth by hydraulics and metabolics during leaf ontogeny. New Phytol. 196, 349-366. doi: 10.1111/j.1469-8137.2012.04273.x

Pantin, F., Simonneau, T., Rolland, G., Dauzat, M., and Muller, B. (2011). Control of leaf expansion: a developmental switch from metabolics to hydraulics. Plant Physiol. 156, 803-815. doi: 10.1104/pp.111.176289

Parent, B., Hachez, C., Redondo, E., Simonneau, T., Chaumont, F., and Tardieu, F. (2009). Drought and abscisic acid effects on aquaporin content translate into changes in hydraulic conductivity and leaf growth rate: a trans-scale approach. Plant Physiol. 149, 2000-2012. doi: 10.1104/pp.108.130682
Poiroux-Gonord, F., Fanciullino, A.-L., Poggi, I., and Urban, L. (2013). Carbohydrate control over carotenoid build-up is conditional on fruit ontogeny in clementine fruits. Physiol. Plant. 147, 417-431. doi: 10.1111/j.1399-3054.2012. 01672.x

Quirk, J., McDowell, N. G., Leake, J. R., Hudson, P. J., and Beerling, D. J. (2013). Increased susceptibility to drought-induced mortality in Sequoia sempervirens (Cupressaceae) trees under Cenozoic atmospheric carbon dioxide starvation. Am. J. Bot. 100, 582-591. doi: 10.3732/ajb.1200435

R Development Core Team (2012). R: A Language and Environment for Statistical Computing. Vienna: R Foundation for Statistical Computing. Available at: http://www.R-project.org

Sadras, V. O., and Milroy, S. P. (1996). Soil-water thresholds for the responses of leaf expansion and gas exchange: a review. Field Crops Res. 47, 253-266. doi: 10.1016/0378-4290(96)00014-7

Schneider, A., Häusler, R. E., Kolukisaoglu, Ü., Kunze, R., van der Graaff, E., Schwacke, R., et al. (2002). An Arabidopsis thaliana knock-out mutant of the chloroplast triose phosphate/phosphate translocator is severely compromised only when starch synthesis, but not starch mobilisation is abolished. Plant J. 32, 685-699. doi: 10.1046/j.1365-313X.2002.01460.x

Sevanto, S., McDowell, N. G., Dickman, L. T., Pangle, R., and Pockman, W. T. (2013). How do trees die? A test of the hydraulic failure and carbon starvation hypotheses. Plant Cell Environ. doi: 10.1111/pce.12141

Shatil-Cohen, A., Attia, Z., and Moshelion, M. (2011). Bundle-sheath cell regulation of xylem-mesophyll water transport via aquaporins under drought stress: a target of xylem-borne ABA? Plant J. 67, 72-80. doi: 10.1111/j.1365-313X.2011. 04576.x

Smith, A. M., and Stitt, M. (2007). Coordination of carbon supply and plant growth Plant Cell Environ. 30, 1126-1149. doi: 10.1111/j.1365-3040.2007.01708.x

Stitt, M., and Zeeman, S. C. (2012). Starch turnover: pathways, regulation and role in growth. Curr. Opin. Plant Biol. 15, 282-292. doi: 10.1016/j.pbi.2012.03. 016

Tadeo, F. R., Cercós, M., Colmenero-Flores, J. M., Iglesias, D. J., Naranjo, M. A., Ríos, G., et al. (2008). "Molecular physiology of development and quality of citrus," in Advances in Botanical Research, eds J.-C. Kader and M. Delseny (San Diego: Elsevier Academic Press), 147-223.

Tang, A.-C., and Boyer, J. S. (2002). Growth-induced water potentials and the growth of maize leaves. J. Exp. Bot. 53, 489-503. doi: 10.1093/jexbot/53.368.489

Tardieu, F., Granier, C., and Muller, B. (2011). Water deficit and growth. Coordinating processes without an orchestrator? Curr. Opin. Plant Biol. 14, 283-289. doi: 10.1016/j.pbi.2011.02.002

Thorpe, M. R., Minchin, P. E. H., Williams, J. H. H., Farrar, J. F., and Tomos, A. D. (1993). Carbon import into developing ovules of Pisum sativum: the role of the water relations of the seed coat. J. Exp. Bot. 44, 937-945. doi: 10.1093/jxb/44. 5.937

Valerio, C., Costa, A., Marri, L., Issakidis-Bourguet, E., Pupillo, P., Trost, P., et al. (2011). Thioredoxin-regulated $\beta$-amylase (BAM1) triggers diurnal starch degradation in guard cells, and in mesophyll cells under osmotic stress. J. Exp. Bot. 62, 545-555. doi: 10.1093/jxb/erq288

Willaume, M., and Pagès, L. (2011). Correlated responses of root growth and sugar concentrations to various defoliation treatments and rhythmic shoot growth in oak tree seedlings (Quercus pubescens). Ann. Bot. 107, 653-662. doi: 10.1093/aob/mcq270

Yazdanbakhsh, N., and Fisahn, J. (2010). Analysis of Arabidopsis thaliana root growth kinetics with high temporal and spatial resolution. Ann. Bot. 105, 783-791. doi: 10.1093/aob/mcq048

Yazdanbakhsh, N., Sulpice, R., Graf, A., Stitt, M., and Fisahn, J. (2011). Circadian control of root elongation and $\mathrm{C}$ partitioning in Arabidopsis thaliana. Plant Cell Environ. 34, 877-894. doi: 10.1111/j.1365-3040.2011.02286.x

Zeeman, S. C., Kossmann, J., and Smith, A. M. (2010). Starch: its metabolism, evolution, and biotechnological modification in plants. Annu. Rev. Plant Biol. 61, 209-234. doi: 10.1146/annurev-arplant-042809-112301

Zhang, Y., Equiza, M. A., Zheng, Q., and Tyree, M. T. (2011). Factors controlling plasticity of leaf morphology in Robinia pseudoacacia: III. biophysical constraints on leaf expansion under long-term water stress. Physiol. Plant. 143, 367-374. doi: 10.1111/j.1399-3054.2011.01504.x

Zhao, M., and Running, S. W. (2010). Drought-induced reduction in global terrestrial net primary production from 2000 through 2009. Science 329, 940-943. doi: $10.1126 /$ science. 1192666 
Conflict of Interest Statement: The authors declare that the research was conducted in the absence of any commercial or financial relationships that could be construed as a potential conflict of interest.

Received: 09 July 2013; accepted: 06 November 2013; published online: 28 November 2013.

Citation: Pantin F, Fanciullino A-L, Massonnet C, Dauzat M, Simonneau T and Muller $B$ (2013) Buffering growth variations against water deficits through timely carbon usage. Front. Plant Sci. 4:483. doi: 10.3389/fpls.2013.00483
This article was submitted to Functional Plant Ecology, a section of the journal Frontiers in Plant Science.

Copyright (C) 2013 Pantin, Fanciullino, Massonnet, Dauzat, Simonneau and Muller. This is an open-access article distributed under the terms of the Creative Commons Attribution License (CC BY). The use, distribution or reproduction in other forums is permitted, provided the original author(s) or licensor are credited and that the original publication in this journal is cited, in accordance with accepted academic practice. No use, distribution or reproduction is permitted which does not comply with these terms. 